\title{
The histone deacetylase inhibitor SAHA acts in synergism with fenretinide and doxorubicin to control growth of rhabdoid tumor cells
}

\author{
Kornelius Kerl ${ }^{1}$, David Ries ${ }^{2}$, Rebecca Unland ${ }^{1}$, Christiane Borchert ${ }^{1}$, Natalia Moreno ${ }^{2}$, Martin Hasselblatt ${ }^{3}$, \\ Heribert Jürgens ${ }^{1}$, Marcel Kool ${ }^{4}$, Dennis Görlich', Maria Eveslage ${ }^{5}$, Manfred Jung ${ }^{6}$, Michael Meisterernst ${ }^{2}$ \\ and Michael Frühwald ${ }^{1,7^{*}}$
}

\begin{abstract}
Background: Rhabdoid tumors are highly aggressive malignancies affecting infants and very young children. In many instances these tumors are resistant to conventional type chemotherapy necessitating alternative approaches.

Methods: Proliferation assays (MTT), apoptosis (propidium iodide/annexin $\mathrm{V}$ ) and cell cycle analysis (DAPI), RNA expression microarrays and western blots were used to identify synergism of the HDAC (histone deacetylase) inhibitor SAHA with fenretinide, tamoxifen and doxorubicin in rhabdoidtumor cell lines.

Results: HDAC1 and HDAC2 are overexpressed in primary rhabdoid tumors and rhabdoid tumor cell lines. Targeting HDACs in rhabdoid tumors induces cell cycle arrest and apoptosis. On the other hand HDAC inhibition induces deregulated gene programs (MYCC-, RB program and the stem cell program) in rhabdoid tumors. These programs are in general associated with cell cycle progression. Targeting these activated pro-proliferative genes by combined approaches of HDAC-inhibitors plus fenretinide, which inhibits cyclinD1, exhibit strong synergistic effects on induction of apoptosis. Furthermore, HDAC inhibition sensitizes rhabdoid tumor cell lines to cell death induced by chemotherapy.
\end{abstract}

Conclusion: Our data demonstrate that HDAC inhibitor treatment in combination with fenretinide or conventional chemotherapy is a promising tool for the treatment of chemoresistant rhabdoid tumors.

\section{Background}

Altered states of chromatin in cancer cells are a promising novel target for therapeutic strategies in the treatment of malignant tumors. Two of many important mechanisms of epigenetic regulation are DNA methylation and histone acetylation, which are closely connected and deregulated in many malignancies [1,2]. HDAC inhibitors counteract cell proliferation and induce apoptosis by altering histone tails and non-histone targets including transcription factors, hormone receptors, signal transducers and molecular chaperones [3]. Recent investigations demonstrated that HDAC-inhibitors (HDACi) display selective toxicity against

\footnotetext{
* Correspondence: michael.fruehwald@klinikum-augsburg.de

'Department of Pediatric Hematology and Oncology, University Childrens'

Hospital Muenster, Muenster, Germany

${ }^{7}$ Childrens' Hospital Augsburg, Swabian Childrens' Cancer Center, Klinikum

Augsburg Stenglinstr 2, Augsburg 86156, Germany

Full list of author information is available at the end of the article
}

tumor cells and sensitize cancer cells to the cytotoxic effects of conventional cytostatic drugs [4-6]. These characteristics have led to the use of several HDACi in a number of single agent or combinatorial clinical trials (more than 100 currently listed) (e.g. in lung, breast bladder cancer, glioblastoma, leukemias and lymphomas) $[7,8]$. Recently the importance of deregulation of epigenetic mechanisms in the development of embryonal tumors such as medulloblastoma, CNS PNET and AT/RT has been demonstrated. Epigenetically active compounds including histone deacetylase inhibitors (HDACi) and demethylating agents (e.g. azacitidine) have been identified as attractive tools for the treatment of embryonal tumors, including rhabdoid tumors [9-11].

Rhabdoid tumors are rare but highly aggressive neoplasms with an incidence peaking between birth and 3 years of age [12]. Rhabdoid tumors of the brain are

\section{Biomed Central}

(C) 2013 Kerl et al.; licensee BioMed Central Ltd. This is an Open Access article distributed under the terms of the Creative Commons Attribution License (http://creativecommons.org/licenses/by/2.0), which permits unrestricted use, distribution, and reproduction in any medium, provided the original work is properly cited. 
termed atypical teratoid/rhabdoid tumors (AT/RT), however rhabdoid tumors can also be found in soft tissues (MRT, malignant rhabdoid tumors) and the kidneys (RTK, rhabdoid tumor kidney). Outcome especially for the youngest patients with rhabdoid tumors remains bleak despite the use of aggressive multimodal chemotherapeutic, radiotherapeutic and surgical interventions (2-year survival rates between $15 \%$ to $55 \%$ for children with AT/RT) $[13,14]$. The majority of rhabdoid tumors exhibit biallelic alterations in the tumor suppressor gene SMARCB1. Apart from SMARCB1 mutations only very few and rather infrequent further alterations have been detected $[15,16]$. Some pathways drivingoncogenesis are defined in rhabdoid tumors: In SMARCB1 negative tumors oncogenes (including MYC and CYCLIND1) [17-20] and tumor cascades such as the sonic hedgehog pathway are activated [19]. Furthermore, $S M A R C B 1$ acts as a direct repressor of the polycomb complex subunit EZH2 [21]. SMARCB1 and EZH2 exhibit antagonistic functions in the regulation of stem cellassociated programs. In rhabdoid tumors loss of SMARCB1 activates those programs [21].

Here we demonstrate that several HDACs, including HDAC1 and 2, are overexpressed in primary rhabdoid tumors and tumor cell lines. The histone deacetylase inhibitor (HDACi) SAHA inhibits cell proliferation of rhabdoid tumor cells by inducing a reversible $\mathrm{G}_{2}$-arrest and subsequently apoptosis. Interestingly SAHA activates tumor pathways, which are already deregulated in rhabdoid tumors (such as MYC, CYCLIND and the pluripotency associated program controlled by $E Z H 2$ ). Based on these results we developed a targeting strategy combining SAHA with fenretinide, which suppresses cyclinD1, and SAHA with conventional chemotherapy. These combinations showed strong synergistic effects on tumor cell growth and represent a promising potential tool for the treatment of rhabdoid tumors.

\section{Methods}

\section{Cell lines}

Rhabdoid tumor cell lines BT12 and BT16 (AT/RT), G401 (rhabdoid tumor of the kidney (RTK)) and A204 (rhabdoid tumor of the liver) were cultured in DMEM high glucose formulation (Invitrogen, Karlsruhe, Germany), supplemented with $10 \%$ fetal bovine serum (South American, Invitrogen), 2\% glutamine (Invitrogen, Karlsruhe, Germany) and no additional antibiotics. The cells were cultured at $37^{\circ} \mathrm{C}$ in a humidified atmosphere with $5 \% \mathrm{CO}_{2}$. A204 and G401 were obtained from ATCC. BT12 and BT16 were a gift from Dr. P. Houghton. Mouse embryonic stem cell (ESC) line $\mathrm{OG}_{2}$ was cultured to the distributors recommendation in DMEM with Glutamax, non-essential aminoacids, mercaptoethanol, PenStrep (all PAA Laboratories, Pasching, Austria) and LIF. For differentiation of ESCs $\mathrm{OG}_{2}$ cells were cultured at least five days without LIF. $\mathrm{OG}_{2}$ cell line was a gift from Hans Schöler (MPI Muenster, Germany).

The identity of all cell lines was verified using ST-PCR. All experiments using cell lines in this publication were at least performed using three independent replicates.

\section{Histone deacetylase inhibitors, Cyclin D inhibitors and chemotherapy}

Suberoylanilindehydroxamic acid (SAHA) (Merck, Darmstadt, Germany), Trichostatin A (TSA) (Sigma, Taufkirchen, Germany), N-(4-hydroxyphenyl)retinamide (4-HPR or fenritinide) (ONBIO, Ontario, Canada, \# 65646-68-6) and 4-Hydroxy-Tamoxifen (4OH-Tam) (Sigma Taufkirchen, Germany, \# H7904) were reconstituted in $100 \%$ ethanol, as a $10 \mathrm{mM}$ solutions. M344 was synthesized by one of us (M.J.). Doxorubicin was purchased from Merck (Merck Millipore, Darmstadt, Germany \# 324380).

\section{Cytotoxicity assay}

Cell suspensions $(5,000$ cells $/ 100 \mu \mathrm{l})$ were seeded into four 96-well-plates. Cells were allowed to reach exponential growth before $100 \mu \mathrm{l}$ of cell culture medium containing the drugs at different concentrations were added. Each drug concentration $(0,0.01,0.1,1,10$ and $100 \mu \mathrm{M})$ was tested in 3 biological replicates. For experiments with combined treatment we used compound 1 (see Tables 1 and 2) in increasing concentrations as in single compound experiments $(0,0.01,0.1,1,10$ and $100 \mu \mathrm{M})$. Compound 2 was used at $1 / 10$ of the concentration of compound 1 . After 0, 24, 48 and $72 \mathrm{hr}$ cells were incubated $3 \mathrm{hr}$ with $10 \mu \mathrm{l} \mathrm{MTT}$ reagent (5 mg/ml MTT dissolved in PBS). Metabolically active cells cleaved the yellow tetrazolium salt to a purple formazan dye. A decrease in the number of living cells correlated with the number of purple formazan crystals. Crystals were dissolved in $100 \mu$ llysis buffer. The specimen was evaluated spectrophotometrically at $570 \mathrm{~nm}$ and a reference of $650 \mathrm{~nm}$ using a Multiskan Ascent multiplate reader (Labsystems, Helsinki, Finland).

\section{Analysis of combined drug effects on cytotoxicity}

To evaluate drug combination effects we analyzed cytotoxicity assay data using the median effect method by Chou and Talalay [22]. We employed three biological replicates of the cytotoxicity assay for each experiment. The fraction of unaffected cells was defined as the proportion of living cells compared to the control. The combination index indicates synergism if $\mathrm{CI}<1$, antagonism for $\mathrm{CI}>1$ and an additive effect for $\mathrm{CI}=1$. Values of the $\mathrm{CI}$ were determined at the $\mathrm{IC}_{50}$ concentration (fraction affected $=0.5$ ). The method was implemented in the statistical software $R$ (Version 2.15.1). 
Table 1 Summarizes results of MTT-tests in different rhabdoid tumor cell lines (A204, G401, BT16) treated with HDAC-inhibitors (SAHA, TSA, M344) cyclin D inhibitors (fenretinide, tamoxifen) as single compounds and in combinations of both classes of compounds

\begin{tabular}{|c|c|c|c|c|c|c|}
\hline Cell line & Compound 1 & Compound 2 & IC $50 \mu \mathrm{M}$ & m & $\mathrm{Cl}$ & $\mathrm{R}^{2}$ \\
\hline A204 & SAHA & -ー-ー-—- & 24.72 & 0.6 & -—-ー-——-ー-—— & 0.72 \\
\hline A204 & M344 & - - & 128.76 & 0.57 & - - - - - & 0.67 \\
\hline A204 & TSA & -—— & 1.83 & 0.43 & -——- & 0.87 \\
\hline A204 & Tam & -— & 2.67 & 0.5 & 一- & 0.86 \\
\hline A204 & Fen & -—- & 1.87 & 0.4 & - - & 0.84 \\
\hline A204 & SAHA & Tam & 0.97 & 0.36 & 0.07 & 0.75 \\
\hline A204 & SAHA & Fen & 1.25 & 0.48 & 0.1 & 0.72 \\
\hline A204 & M344 & Tam & 0.97 & 0.48 & 0.19 & 0.56 \\
\hline A204 & M344 & Fen & 0.28 & 0.24 & 0.01 & 0.88 \\
\hline A204 & TSA & Tam & 0.16 & 0.2 & 0.08 & 0.77 \\
\hline A204 & TSA & Fen & 0.1 & 0.24 & 0.05 & 0.73 \\
\hline G401 & SAHA & - & 31.82 & 0.44 & -— & 0.87 \\
\hline G401 & Tam & - & 3.13 & 0.53 & 一一 & 0.89 \\
\hline G401 & Fen & 一一 & 3.37 & 0.54 & -——- & 0.85 \\
\hline G401 & SAHA & Tam & 1.42 & 0.3 & 0.06 & 0.9 \\
\hline G401 & SAHA & Fen & 1.65 & 0.54 & 0.09 & 0.91 \\
\hline BT16 & SAHA & -ー-ーー-ー-ー & 8.39 & 0.64 & -—-—-二 & 0.93 \\
\hline BT16 & Tam & - & 2.09 & 0.75 & -——— & 0.9 \\
\hline BT16 & Fen & -二-二- & 2.74 & 0.5 & -— & 0.91 \\
\hline BT16 & SAHA & Tam & 0.11 & 0.44 & 0.02 & 0.87 \\
\hline BT16 & SAHA & Fen & 0.43 & 0.52 & 0.06 & 0.86 \\
\hline
\end{tabular}

Table shows results after $72 \mathrm{~h}$ of treatment.

$\mathrm{Cl}=$ combination index [22].

\section{Western blots}

For differentiation of mouse embryonic stem cell line $\mathrm{OG}_{2}$ cells were grown without LIF. After $5 \mathrm{~d}$ cells were harvested and lysed using Biorupture (Diagenode; Liege, Belgium). SDS page was performed as described [9]. Briefly tris/glycine gels were used for 1-D separation (20 mg protein per lane). Semidry transfer was carried out for $1 \mathrm{~h}$ at $18 \mathrm{~V}$ using tris/glycine buffer [9]. Western-blots were scanned and aligned with the Photoshop 6.0 channel mixer (Adobe).

\section{Antibodies for western blots}

Hdac1 (ab7028) rabbit polyclonal 65 kDA, 1:500, (Abcam, Cambridge UK)

Table 2 Summarizes results of MTT-tests in different rhabdoid tumor cell lines (A204, G401, BT16) treated with HDAC-inhibitors (SAHA, TSA, M344) or doxorubicin as single compounds or in combinations of both compounds

\begin{tabular}{|c|c|c|c|c|c|c|}
\hline Cell line & Compound 1 & Compound 2 & IC $50 \mu \mathrm{M}$ & $m$ & $\mathrm{Cl}$ & $\mathrm{R}^{2}$ \\
\hline A204 & SAHA & -ー-ー-ー-—-———- & 24.72 & 0.6 & -—-—-—-—-—- & 0.72 \\
\hline A204 & DOXO & -二-二-二-二-二- & 6.48 & 0.37 & - - & 0.72 \\
\hline A204 & DOXO & SAHA & 0.16 & 0.22 & 0.02 & 0.76 \\
\hline G401 & SAHA & ー—————— & 31.82 & 0.44 & - - & 0.87 \\
\hline G401 & DOXO & - - - - - & 0.67 & 0.38 & -———- & 0.77 \\
\hline G401 & DOXO & SAHA & 0.03 & 0.17 & 0.03 & 0.85 \\
\hline BT16 & SAHA & --二-二-二-二-二- & 8.39 & 0.64 & -二-二-二-— & 0.93 \\
\hline BT16 & DOXO & -————— & 0.13 & 0.18 & - - & 0.83 \\
\hline BT16 & DOXO & SAHA & 0.003 & 0.2 & 0.02 & 0.81 \\
\hline
\end{tabular}

The $\mathrm{Cl}$ values have been determined at the respective IC50 concentration. $\mathrm{Cl}<1$ indicates synergism. $\mathrm{R}^{2}$ denotes the coefficient of determination of the linear regression in the median effect plot. 
Hdac2 (ab12169) mouse monoclonal, 56 kDA, 1:500, (Abcam, Cambridge UK)

$\alpha$-Tubulin (sc 23948) mouse monoclonal, $50-55 \mathrm{kDa}$, 1:1000, (Santa Cruz, Heidelberg, Germany)

Oct4 (sc-8628) goat polyclonal, 43-50 kDa, 1:500,

(Santa Cruz, Heidelberg, Germany)

CyclinD1 (sc 754), rabbit polyclonal, $38 \mathrm{kDa}, 1: 500$,

(Santa Cruz, Heidelberg, Germany)

H3K27me3 (6002), mouse monoclonal, $18 \mathrm{kDa}, 1: 500$, (Abcam, Cambridge UK)

Ezh2 (AC22), mouse monoclonal, $98 \mathrm{kDa}, 1: 500$, (Cell Signaling, Danvers, USA)

\section{Apoptosis detection and cell cycle analysis}

Effects on apoptosis induction were analyzed in A204 cells. Cells were incubated in $75 \mathrm{~cm}^{2}$ tissue flasks with the drugs for 24, 48 and $72 \mathrm{hr}$. A204 cells were treated with ethanol (control), with SAHA $(1 \mu \mathrm{M}$ or $10 \mu \mathrm{M})$, fenretinide $(1 \mu \mathrm{M}$ or $10 \mu \mathrm{M})$ or a combination of SAHA $(1 \mu$ or $10 \mu \mathrm{M})$ and fenretinide $(1 \mu \mathrm{M}$ or $10 \mu \mathrm{M})$. All experiments were at least performed in biological triplicates. An annexin-V-FITC apoptosis detection kit was employed (BD Biosciences, Heidelberg, Germany). Cells were washed with PBS and fluorescein isothiocyanateconjugated annexin- $\mathrm{V}$ and propidiumiodide were added. Cells were then incubated at room temperature $(15 \mathrm{~min})$ and analyzed by flowcytometry, using a Facscalibur (BD Biosciences, Heidelberg, Germany). For cell cycle analysis cells were cultured and treated with compounds as described before, incubated with DAPI and measured using the Facscalibur(BD Biosciences, Heidelberg, Germany).

\section{CDNA microarray experiments and statistical analysis}

A204 cells were treated with $10 \mu \mathrm{mol}$ SAHA or equal amounts of ethanol (control). SAHA treated A204 cells and control samples were used as biological triplicates. After $12 \mathrm{~h}$ incubation cells were harvested and RNA was isolated by using an RNAeasy mini kit (Qiagen, Hilden, Germany). Affymetrix Gene Chip human 1.0 was used. Microarray data were analyzed using GeneSpring GX Software (Agilent, Santa Clara, USA). Microarray data complywiththe MIAME standard. Data were corrected for background noise, normalized and summarized using ExonRMA16 Algorithm. Following quality control was performed.

To identify differentially expressed genes in SAHA treated compared to untreated A204 cells we used an unpaired $t$-test. For further analysis we considered genes with a students $t$-test $\mathrm{p}$-value of $<0.05$ and a foldchange of $\geq 2$. Prior published microarray data were used as supplied, as processed lists or downloaded from GEO $[23,24]$. Analysis of enriched GeneSets with GSEA (http://www.broadinstitute.org/gsea/index.jsp). GeneSets were downloaded from the MSig database [23,24]. To process the data, in-house scripts were employed.
For analysis of HDAC RNA expression we compared available data from geo database of primary rhabdoid tumors [25] to expression data from normal brain tissue [26]. These data were MAS5.0 normalized. HDACs in primary rhabdoid tumor were compared to normal brain tissue from different localizations of the brain.

Microarray data were confirmed using real-time qPCR (Step One plus, Applied Biosystem, Carlsbald, USA). RNA was isolated as described above from G401 cell treated with SAHA for $12 \mathrm{~h}$. RT-PCR was performed using Takara RT-PCR kit (Clontec Laboratories, Mountain View, USA) according to the manufacturer's protocol. For Real-time PCR we used Fast SYBR green (Applied Biosystem, Carlsbad, USA).

\section{Primers used for real-time PCR}

hHMGB2 for: CGG-GGC-AAA-ATG-TCC-TCG-TA

hHMGB2rev: CGG-AAG-AGT-CCG-GGT-GTT-T

hBLM for: CAG-ACT-CCG-AAG-GAA-GTT-GTA-TG

hBLM rev: TTT-GGG-GTG-GTG-TAA-CAA-ATG-AT

hRFC3 for: GTG-GAC-AAG-TAT-CGG-CCC-TG

hRFC3 rev: TGA-TGG-TCC-GTA-CAC-TAA-CAG-AT

hMELK for: TCT-CCC-AGT-AGC-ATT-CTG-CTT

hMELK rev: TGA-TCC-AGG-GAT-GGT-TCA-ATA-GA

hMCM4 for: GAC-GTA-GAG-GCG-AGG-ATT-CC

hMCM4 rev: GCT-GGG-AGT-GCC-GTA-TGT-C

hMCM7 for: CCT-ACC-AGC-CGA-TCC-AGT-CT

hMCM7 rev: CCT-CCT-GAG-CGG-TTG-GTT-T

hPOLD3 for: GAG-TTC-GTC-ACG-GAC-CAA-AAC

hPOLD3 rev: GCC-AGA-CAC-CAA-GTA-GGT-AAC

\section{Results}

HDACs are highly expressed in primary rhabdoid tumors and rhabdoid tumor cell lines

Aberrant expression of different HDACs has been observed in various tumors $[1,2,9]$ and has been linked to tumor growth progression and poor outcome [27]. To compare the expression of HDACs in primary rhabdoid tumors and normal brain tissue we analyzed RNA expression profiles of AT/RT tissue [25] and normal brain tissue (Figure $1 \mathrm{~A}$ and $\mathrm{B}$ and Additional file 1: Figure S1) [26] from datasets available in the GEO database $[25,26]$. Several HDAC including HDAC1, 2, 5, 6, 9 and SIRT1 are highly expressed in primary AT/RT (Figure 1A and B, Additional file 1: Figure S1).

Group 1 HDACs (including HDAC1, 2 and 3) are highly expressed in embryonic stem cells (ESCs) and down regulated during differentiation (Figure 1C) [28]. Comparing protein expression in different SMARCB1 negative rhabdoid tumor cell lines (A204, G401, BT16, BT12) with ESCs $\left(\mathrm{OG}_{2}\right.$; as a control with known highly expressed HDAC1 and HDAC2) demonstrate that group 1 HDAC levels are similarly expressed in rhabdoid tumors and ESC (Figure 1D). 

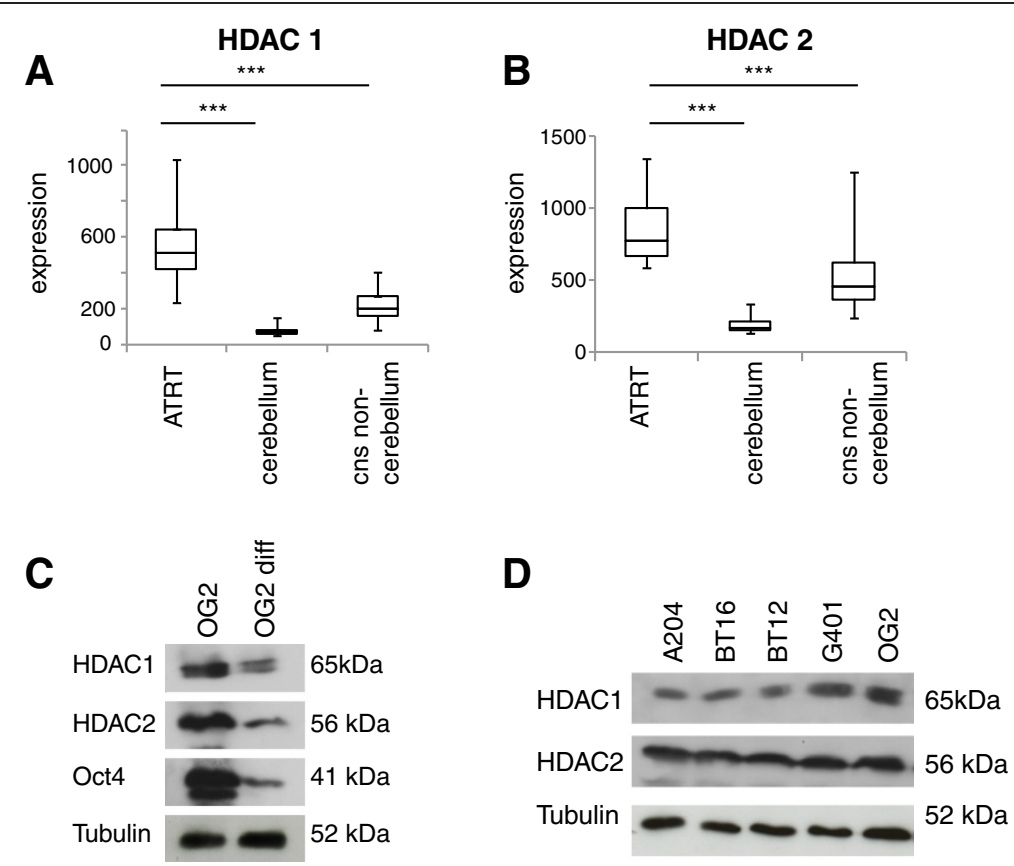

Figure 1 Expression of HDACs in rhabdoid tumors. A and B. HDACs are highly expressed on RNA level in primary rhabdoid tumors $(n=23)$ in comparison to differentiated brain tissue $(n=169)$ using available gene expression profiles of AT/RT [24] and different normal brain tissues [26]. C. HDAC1 and HDAC2 are highly expressed in mouse embryonic stem cells (ESC cell line $\mathrm{OG}_{2}$ ) and are down regulated after five days of differentiation (without LIF). D. Western-Blots of SMARCB1 negative rhabdoid tumor cell lines (BT12, BT16, A204, G401) show high expression of HDAC 1 and HDAC 2, which is comparable to the expression of these HDACs in embryonal stem cells $\left(\mathrm{OG}_{2}\right)$.

Overall these data demonstrate that several HDAC are highly expressed in SMARCB1 negative primary tumors and tumor cell lines.

The non-selective histone deacetylase inhibitor SAHA induces reversible $\mathrm{G}_{2}$-arrest and apoptosis in SMARCB1 negative tumors

To evaluate whether high expression levels of HDACs correlate with cell cycle progression in rhabdoid cells we inhibited HDACs using the non-selective HDAC inhibitor (HDACi) SAHA (suberoylanilindehydroxamic acid) [9]. HDACi cause strong inhibition of cell growth in high-risk embryonal tumors of the central nervous system, including rhabdoid tumors $[9,29]$. Here we demonstrate that SAHA transiently (after $18 \mathrm{~h}$ ) induces $\mathrm{G}_{2}$ arrest (Figure 2B, dashed, green line and Table 3). In contrast to published data demonstrating that the $G_{2}$ arrest due to HDACi maybe a sign of resistance of cell lines to HDACi [30], rhabdoid tumor cell lines overcome the $\mathrm{G}_{2}$ arrest after $72 \mathrm{~h}$ (Figure 2B, dotted, blue line). After overcoming $\mathrm{G}_{2}$ arrest (Figure 2A and Additional file 2: Figure S2a) apoptosis is induced (Figure $2 \mathrm{~B}$ and Additional file 2: Figure S2b).

\section{SAHA induces expression of RB-, MYC- and pluripotency-associated genes}

One major goal of our investigation was to identify potential combinatorial approaches of SAHA with other compounds based on molecular in vitro findings.

To analyze known deregulated pathways in rhabdoid tumors, like RB and MYC, we performed microarray analysis of A204 after treatment with HDAC inhibitor SAHA. With a threshold of a 2-fold change we detected 1125 genes downregulated and approximately the same number of genes upregulated (1.119 genes). We analyzed known deregulated pathways in rhabdoid tumors, like cdk4/6-cyclinD-RB- and $M Y C$, using gene set enrichment analysis (GSEA). We expected due to the observed growth arrest that these pro-proliferative pathways were downregulated after HDACi treatment [31]. Surprisingly these gene sets $(M Y C, R B$, stem cell programs; Figures $3 \mathrm{~A}-\mathrm{C}$ ) were not downregulated, but instead even more pronounced and highly significantly enriched following SAHA application. In these gene sets we demonstrated that target genes of MYC (Figure 3A), the RB-pathway (Figure 3B and Additional file 3: Figure S3) and genes associated with pluripotency (Figure $3 \mathrm{C}$ ) are upregulated in SAHA-treated cells, indicating that not only apoptosis but also pro-proliferative pathways are 


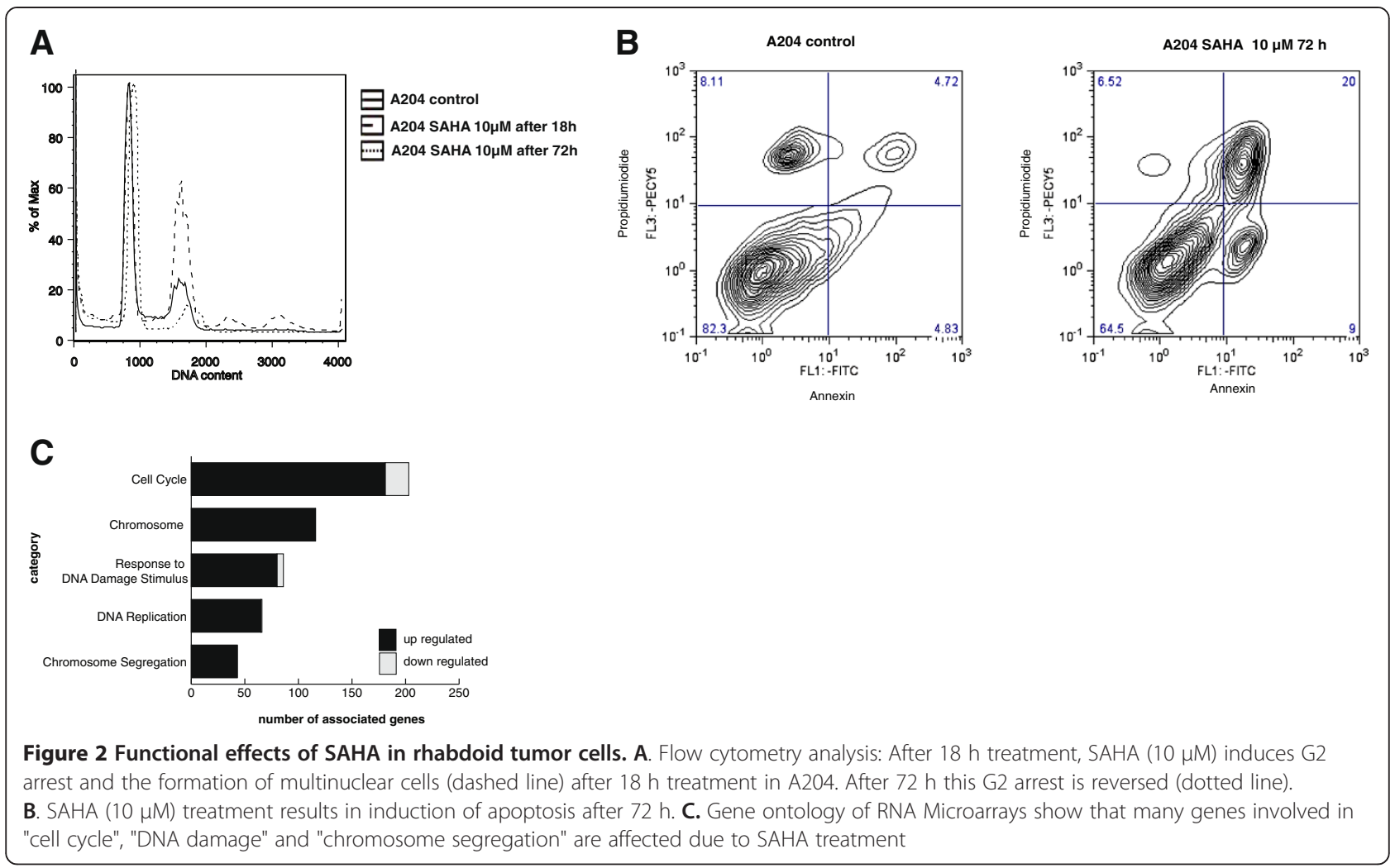

induced by SAHA. Microarray data were validated in A204 and G401 rhabdoid tumor cell lines using qPCR (Additional file 3: Figure S3).

\section{SAHA synergizes with fenretinide in inhibiting rhabdoid cell growth}

Treatment of rhabdoid tumor cell line A204 with SAHA upregulates RB- and MYC- target genes and the pluripotency-associated program controlled by EZH2. These genes and gene pathways induce pro-proliferative signals in rhabdoid tumors [21,32]. Based on these results we developed a combined targeting strategy. We tested treatment of SAHA in combination with tamoxifen and fenretinide. Both compounds affect the transcription as well as the protein stability of cyclin D1 [33,34]. Furthermore

Table 3 Shows \%-values of G1-, S-, G2-phase cells of two different rhabdoid tumor cell lines (A204, G401) treated with $10 \mu \mathrm{M}$ SAHA for $18 \mathrm{~h}$ or $72 \mathrm{~h}$

\begin{tabular}{llll}
\hline Cell line & G1-phase $\%$ & S-phase $\%$ & G2-phase \% \\
\hline A204 control & $57.0+/-1.2$ & $21.1+/-0.9$ & $22.0+/-2.3$ \\
A204 SAHA 18 h & $43.3+/-2.1$ & $10.5+/-0.6$ & $46.3+/-3.4$ \\
A204 SAHA 72 h & $79.1+/-1.9$ & $5.3+/-0.4$ & $15.6+/-0.9$ \\
G401 control & $45.8+/-1.0$ & $39.2+/-1.6$ & $14.9+/-0.9$ \\
G401 SAHA 18 h & $56.4+/-7.6$ & $12.8+/-0.2$ & $30.8+/-2.6$ \\
G401 SAHA 72 h & $76.2+/-5.5$ & $10.3+/-2.8$ & $13.5+/-0.6$ \\
\hline
\end{tabular}

we combined SAHA with conventional chemotherapy (doxorubcin).

The Rb-pathway is controlled by phosphorylation of $\mathrm{Rb}$ by cdk4/6/cyclin D1. Dragnevet al showed that targeting cyclin $\mathrm{D} 1$ by fenretinide leads to $\mathrm{G}_{0}$-arrest and apoptosis in rhabdoid cell lines [34]. We compared cell proliferation effects of SAHA in rhabdoid cell lines as a single compound and combined treatment using SAHA with drugs that inhibit cyclinD1 (fenretinide and tamoxifen). The combination of these two groups of compounds demonstrated strong synergistic effects resulting in a significant decrease of the $\mathrm{IC}_{50}$ values compared to the $\mathrm{IC}_{50}$ of HDACi alone (Figure 4A-C and Table 1). The combination of 4-Hydroxytamoxifen (4-OH-Tam) and HDACi showed strong synergism, however the combination of fenretinide with HDACi reduces the $\mathrm{IC}_{50}$ values of the HDACi to a nanomolar range. Different HDAC inhibitors (SAHA, TSA, M344) in combination with fenretinide or tamoxifen in different rhabdoid tumor cell lines (Figure 4A$\mathrm{C}$ and Table 1) showed strong synergistic effects. Using high concentrations of these inhibitors no synergism is observed due to cell toxicity of each single compound.

We additionally tested a treatment strategy combining doxorubicin with SAHA. This resulted in a clear reduction of doxorubicin $\mathrm{IC}_{50}$ values (Figure $4 \mathrm{E}$ and F; Table 2).

Using apoptosis assays we demonstrated, that the combination of SAHA and cyclinD1 inhibitors acts synergistically due to induction of apoptosis (Figure 5A-F and Table 4). 


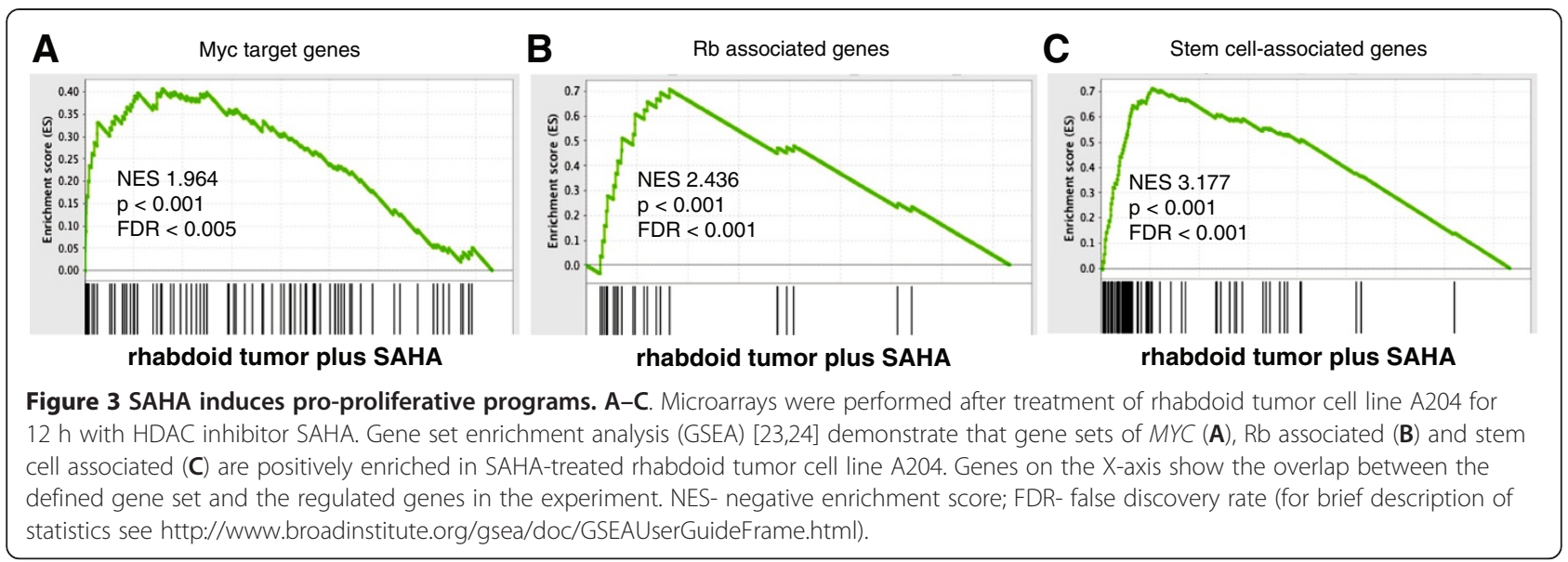

\section{Discussion}

Conventional chemotherapeutics remain disappointing in the treatment of rhabdoid tumors [35], making alternative approaches highly needed. Rhabdoid tumors seem to lack other mutations than those found in SMARCB1
$[15,36]$, suggesting epigenetic changes high likely in this tumor entity $[15,37]$.

One of the most promising epigenetic targets for therapy of rhabdoid tumors is the inhibition of histone deacetylases by small compounds (histone deacetylase
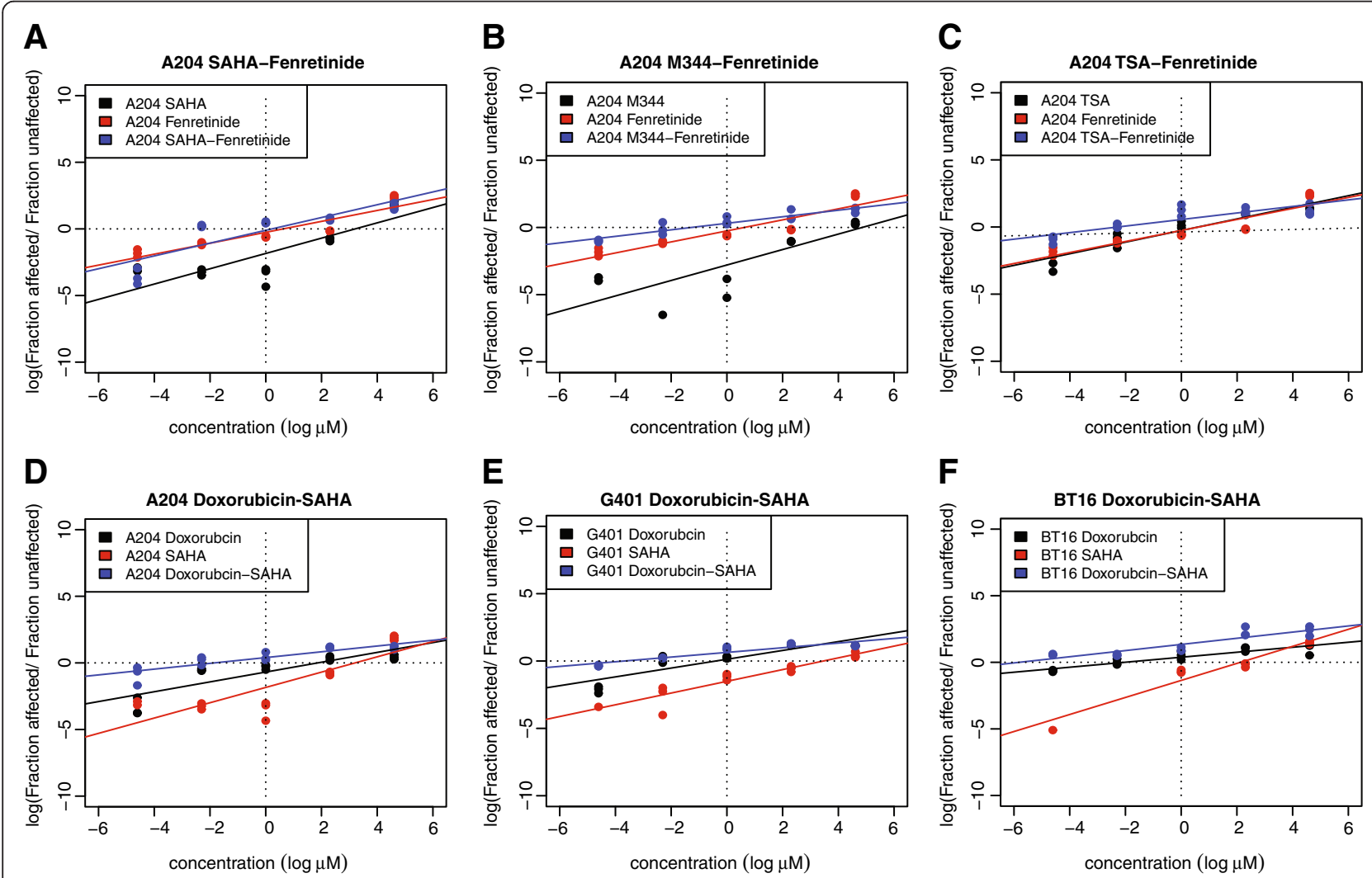

Figure 4 Synergistic growth inhibition using SAHA with fenretinide and with conventional chemotherapy in rhabdoid tumor cell lines.

A, B, C. HDACi (SAHA, M344, TSA) were used in concentrations ranging from $0.01 \mu \mathrm{M}$ to $100 \mu \mathrm{M}$. In single compound experiments fenretinide was used in the same increasing concentration $(0.01 \mu \mathrm{M}$ to $100 \mu \mathrm{M})$. In the combined approach we used HDACi (SAHA, M344, TSA) from $0.01 \mu \mathrm{M}$ to $100 \mu \mathrm{M}$ in combination with $10 \%$ fenretinide $(0.001 \mu \mathrm{M}$ to $10 \mu$ ). Median effect plots show that, SAHA and other HDACi (M344 and TSA) act strongly synergistic with the cyclinD inhibitor fenretinide (for Cl-values see also table 1). D, E, F. Three different rhabdoid tumor cells lines (A204, G401, BT16) were treated with SAHA, doxorubicin or combinations of both compounds for $72 \mathrm{~h}$ and were analysed using MTT-assays. Median effect blots demonstrate that conventional chemotherapy (doxorubicin) acts synergistically with SAHA on inhibiting cell proliferation. 

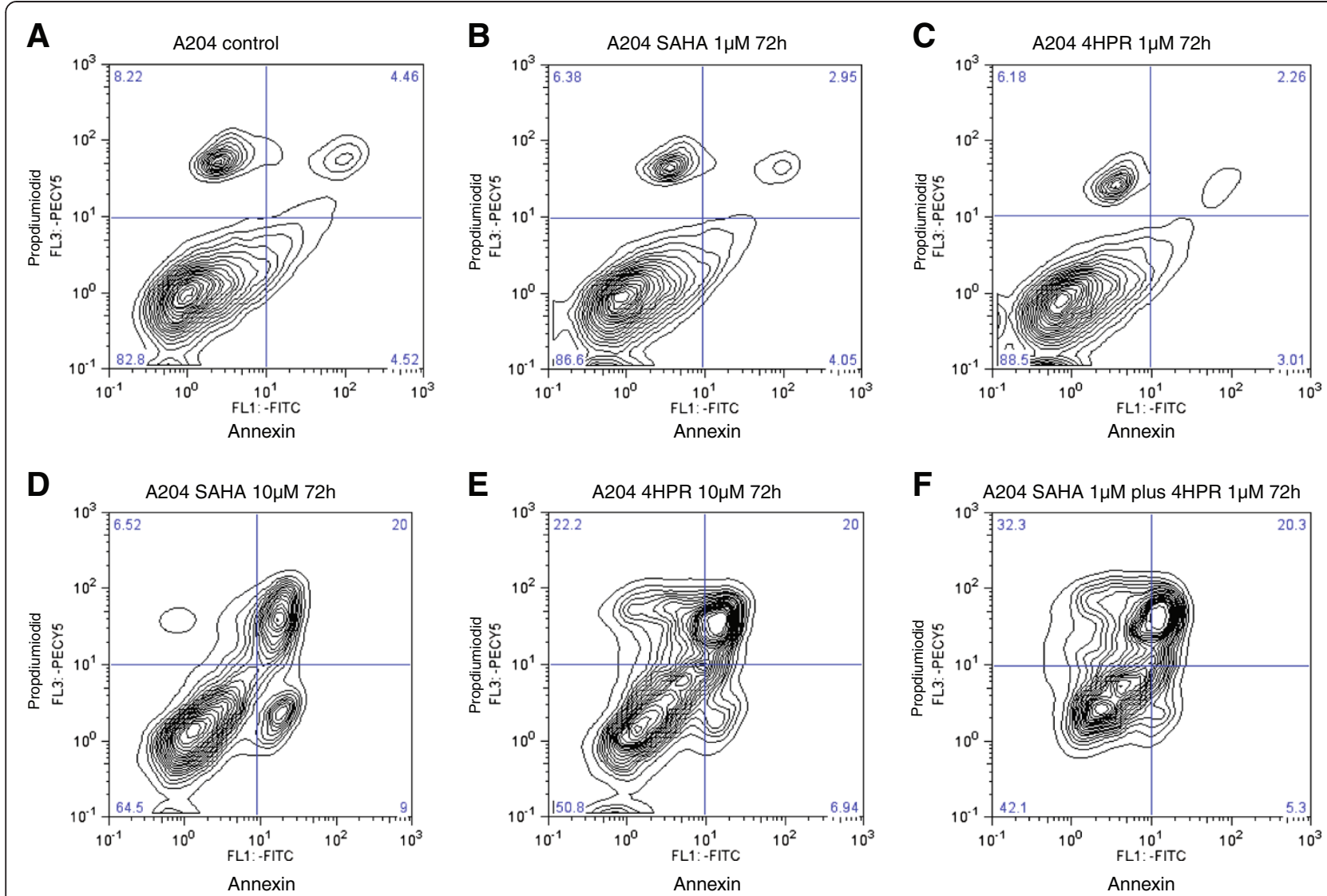

Figure 5 HDACi and fenretinide act synergistic on induction of apoptosis. A204 cells were treated for $72 \mathrm{~h}$ with HDACi SAHA (1 $\mu \mathrm{M}, 10 \mu \mathrm{M})$ fenretinide (4HPR) $(1 \mu \mathrm{M}, 10 \mu \mathrm{M})$ or combinations of both compounds. Low concentrations (1 $\mu \mathrm{M})$ of SAHA (B) or fenretinide (C) as single treatment do not induce apoptosis compared to control $(\mathbf{A})$. High concentrations $(10 \mu \mathrm{M})$ of SAHA (D) or high concentrations of fenretinide $(\mathbf{E})$, as well as low concentrations of combined treatment of SAHA plus fenretinide, induce apoptosis (F).

inhibitors (HDACi)) [9,11,38]. The rationale to use HDACi in rhabdoid tumors is simple. First, several HDACs (including HDAC 1, 2, 5, 6, 9 and SIRT1) are, like in many other tumor entities [1,2], overexpressed in rhabdoid tumors. Second, unselective HDACi inhibit cell growth, induce apoptosis and autophagy in rhabdoid tumor cell lines $[9,38,39]$. Third, HDACi lead to increased acetylation of histones making chromatin more accessible to transcription factors. SMARCB1, one of the core subunits of the SWI/ SNF complex, is involved in ATP-dependent chromatin remodeling and modulation of accessibility of chromatin to transcription factors. As HDAC inhibition has been shown to restore imprinted tumor suppressors such as CDKN1C in rhabdoid tumors [39], we hypothesized that HDACi

Table 4 Shows percentage of rhabdoid tumor cell lines (A204, G401) surviving, in early or in late apoptosis after $72 \mathrm{~h}$ of treatment with SAHA as a single compound or in combination with 4HPR

\begin{tabular}{|c|c|c|c|c|c|c|}
\hline Cell line & Control & SAHA $1 \mu \mathrm{M}$ & SAHA $10 \mu \mathrm{M}$ & 4HPR $1 \mu \mathrm{M}$ & 4HPR $10 \mu \mathrm{M}$ & $\begin{array}{l}\text { SAHA } 1 \mu \mathrm{M} \\
\text { 4HPR } 1 \mu \mathrm{M}\end{array}$ \\
\hline \multicolumn{7}{|l|}{ A204 } \\
\hline$\%$ surviving cells & $85.1+/-2.6$ & $87.5+/-0.2$ & $66.7+/-0.6$ & $87.8+/-1.4$ & $49.1+/-1.1$ & $40.2+/-0.8$ \\
\hline \% early apoptosis & $4.8+/-0.1$ & $4.1+/-0.2$ & $8.5+/-0.2$ & $6.2+/-1.0$ & $7.7+/-0.5$ & $6.9+/-0.4$ \\
\hline \% late apoptosis & $10.1+/-2.5$ & $8.4+/-0.3$ & $24.8+/-1.5$ & $8.3+/-0.7$ & $43.1+/-0.7$ & $6.9+/-0.4$ \\
\hline \multicolumn{7}{|l|}{ G401 } \\
\hline$\%$ surviving cells & $90.3+/-0.8$ & $91.2+/-1.5$ & $64.7+/-2.9$ & $92.3+/-2.2$ & $60.0+/-2.2$ & $62.9+/-3.2$ \\
\hline$\%$ early apoptosis & $5.2+/-0.6$ & $5.1+/-0.9$ & $23.6+/-0.9$ & $4.1+/-1.2$ & $26.9+/-0.7$ & $27.3+/-1.3$ \\
\hline$\%$ late apoptosis & $4.5+/-0.2$ & $3.8+/-0.7$ & $11.7+/-2.1$ & $3.6+/-1.0$ & $13.1+/-1.4$ & $9.8+/-4.2$ \\
\hline
\end{tabular}


might generally compensate the missing chromatin remodeling function caused by $S M A R C B 1$ loss. We investigated if HDAC inhibition leads to general restoration of known deregulated pathways in rhabdoid tumor cell lines (like $M Y C$ - or $R B$-pathways). Gene set enrichment analysis (GSEA) demonstrated that gene programs, which are deregulated by loss of SMARCB1 in rhabdoid tumors (MYC, cyclin D1 and the pluripotency program) are further upregulatedfollowing SAHA treatment. These results suggest that HDAC inhibitors not only restore imprinted tumor suppressor genes, like $C D K N 1 C$ [39], but also, as an "unselective transcription activator" increase expression of deregulated oncogenes in rhabdoid tumors. Based on these results we developed a combined targeting strategy using SAHA with conventional chemotherapeutics and compounds affecting cyclin D1-expression. The cdk4/cdk6/ cyclin D1 pathway is directly controlled by $S M A R C B 1$ [17,20,32]. Cyclin D1 forms a complex with cdk4/cdk6, which than phosphorylates Rb, thereby activates E2F1 and promotes cell cycle progression [40].

Combined targeted therapy of rhabdoid tumors makes sense from a molecular biology and from a clinical point of view. In other tumor entities including a subset of medulloblastomas individual pathways such as the sonic hedgehog pathway $(\mathrm{SHH})$ seem to drive tumorigenesis [41]. This type of medulloblastoma has been shown in vivo to be highly responsive to small molecular compounds specifically inhibiting the sonic hedgehog pathway [42].

In rhabdoid tumors the situation might be somewhat different as biallelic mutation of the chromatin remodeling factor SMARCB1 deregulates multiple tumor pathways ( $\mathrm{SHH}$, polycomb mediated pathways and $\mathrm{Rb}$ mediated pathways) (Figure 6). As we have demonstrated inhibition of one deregulated process (e.g. HDAC inhibition) may fail to target other deregulated cascades or even upregulate those pathways (like cdk4/6/cyclin D) due to an "unselective" transcriptional activation induced by HDACi. The current knowledge of the function of molecular pathways, the clinical behavior of rhabdoid tumors and our presented results make combined targeted therapy highly attractive and necessary for rhabdoid tumors. Inhibition of cyclinD1 and HDAC seems to affect two different deregulated targets in rhabdoid tumors, act synergistically and might be an attractive therapeutic approach for rhabdoid tumor treatment.

HDAC inhibitors as well as fenretinide have been evaluated in recent clinical phase I/II studies.

The bioavailability of fenretinide in children has been discussed controversially. In a recent study in pediatric neuroblastoma patients on fenretinide showed low bioavailability [43]. New formulations of fenretinide are presently evaluated [43].

Currently, over 100 phase I/II clinical trials are underway evaluating the safety and efficacy of HDAC inhibitors $[44,45]$. Clinical approaches with single use of HDACi show side effects like myelosuppression, fatigue and other toxicity and demonstrate only moderate effects on tumor growth of most tumor entities tested so far [45].

SAHA has been the first HDACi approved by the FDA and has been tested in several clinical trials. In clinical
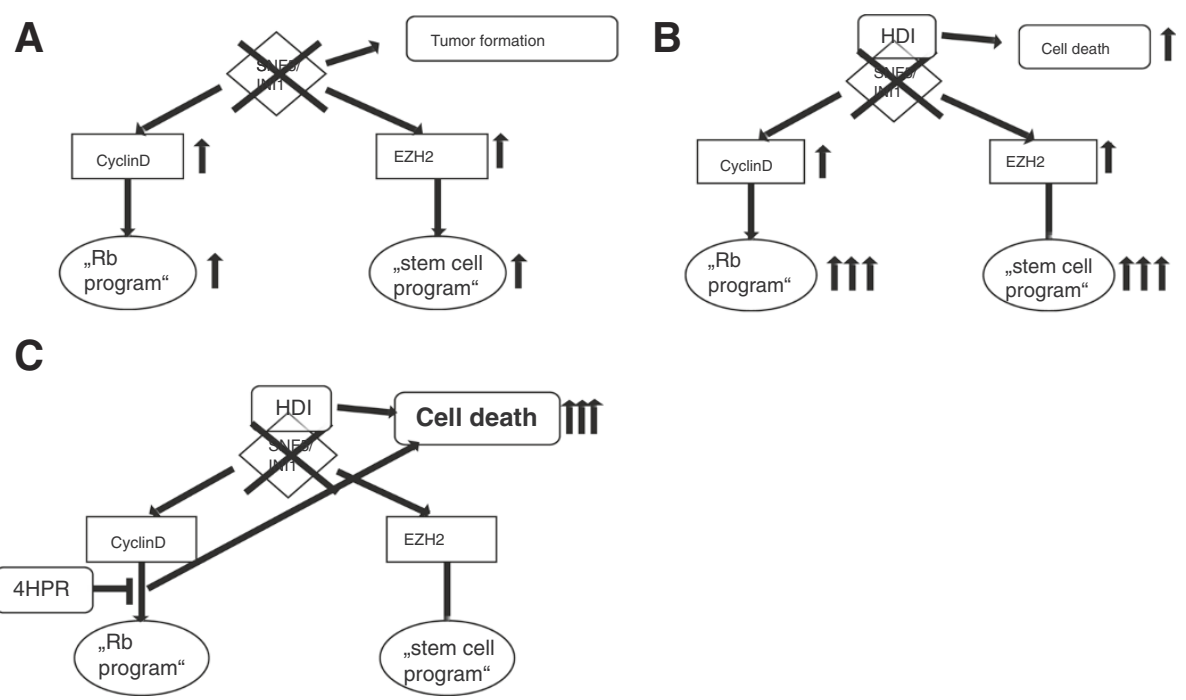

Figure 6 Model of synergism of HDACi and fenretinide in rhabdoid tumors. A. Loss of INI1 in rhabdoid tumors lead to tumor formation by deregulating different tumor pathways like cyclin D-Rb-pathway and "EZH2-stem cell program". B. HDAC inhibition in rhabdoid tumor cell lines induces apoptotic cell death. On the other hand HDAC inhibition induces genes and pathways which are known to be already deregulated in this tumor entity (like cyclinD1 and "stem cell program"). 6. HDAC inhibition induces Rb-program by induction of CDK4/6/cyclin D1. Blocking HDAC mediated cyclin D induction by fenretinide results in dramatic induction of apoptosis. The combined inhibition of HDACs and cyclin D synergizes in the induction of apoptosis. 
studies the effect of single use of HDACi seems to be minor, so combined strategies of SAHA with other compounds are tested [29]. In adult AML patients phase II studies showed that combined treatment of vorinostat (SAHA) with idarubicine and cytarabine is safe [46]. Other phase I/II studies demonstrated the safety of SAHA in combinations with paclitaxel and bevacizumab [47], with gemtuzumab [48] and bortezomib [49]. Vorinostat in pediatric patient cohorts has been well tolerated [50].

\section{Conclusion}

To summarize our results we have demonstrated that

1. HDACi not only restore tumor suppressor genes like $C D K N 1 C$, but also induce pro-proliferative genes like CyclinD1, MYC and pluripotency associated genes

2. therapy of HDACi with cyclinD1 inhibitors and combined use of HDACiwith conventional chemotherapy demonstrates strong synergism on inhibition of tumor cell growth.

These experiments provide the rationale for a promising new therapeutic approach for the treatment of therapy resistant rhabdoid tumors.

\section{Additional files}

Additional file 1: Figure S1. HDACs are highly expressed on RNA level in primary rhabdoid tumors $(n=23)$ in comparison to differentiated brain tissue $(n=169)$ using available gene expression profiles of AT/RT [24] and different normal brain tissues [26]. In addition to Figure 1 HDAC 5, HDAC 6 and SIRT1 are significantly upregulated in rhabdoid tumors compared to normal brain tissue.

Additional file 2: Figure S2. A. Flow cytometry analysis: After $18 \mathrm{~h}$ treatment, SAHA (10 $\mu \mathrm{M})$ induces $\mathrm{G}_{2}$ arrest and the formation of multinuclear cells (dashed line) after $18 \mathrm{~h}$ treatment in G401. After $72 \mathrm{~h}$ this $G_{2}$ arrest is reversed (dotted line). B. SAHA $(10 \mu \mathrm{M})$ treatment results in induction of apoptosis in G401 cells after $72 \mathrm{~h}$.

Additional file 3: To confirm microarray data G401 cells were treated with SAHA $(10 \mu \mathrm{M})$ for $12 \mathrm{~h}$. QPCR shows upregulation of "Rb-pathway" associated genes.

\section{Abbreviations \\ AT/RT: Atypical teratoidrhabdoid tumors; CDK: Cyclindependent kinase; CDKi: Cyclin dependent kinase inhibitor; FDA: Food and Drug Administration; FDR: False discovery rate; HDAC: Histone deacetylase; HDACi: Histone deacetylase inhibitor; 4-HPR: 4-hydroy(phenyl)retinamide; MTT- 3: (4,5- Dimethylthiazol-2yl)-2,5-diphenyltetrazoliumbromid; NES: Negative enrichment score; SAHA: Suberoylanilindehydroxamic acid; Tam: Tamoxifen.}

\section{Competing interests}

The authors declare that they have no competing interests.

\section{Authors' contributions}

$\mathrm{KK}, \mathrm{RU}, \mathrm{CB}, \mathrm{NM}, \mathrm{MH}, \mathrm{MJ}$ conducted experiments; KK, HJ, MM, MF designed experiments; DR and MK analyzed expression data; DG and ME set up statistical analyses; KK, HJ, MM, MF wrote the manuscript. All authors read and approved the final manuscript.

\section{Acknowledgements}

Microarray analysis were performed by the Integrated Functional Genomics Core Unit of the Interdisciplinary Center for Clinical Research at the Medical Faculty of the University of Muenster.

We acknowledge support by Deutsche Forschungsgemeinschaft and Open Access Publication Fund of University of Muenster.

\section{Grant support}

This work was supported by the fund "Innovative Medical Research"of the University of Muenster Medical School, and by the Sonja Wasowicz Stiftung im Stifterverband für die Deutsche Wissenschaft(Germany). MH is supported by IZKF Muenster (HA3/016/11).

\section{Availability of data}

Microarray data of this study are available on: http://www.ncbi.nlm.nih.gov/ geo/query/acc.cgi?acc=GSE37373.

\section{Author details}

'Department of Pediatric Hematology and Oncology, University Childrens' Hospital Muenster, Muenster, Germany. ${ }^{2}$ Institute of Molecular Tumor Biology, WestfalianWilhelms University, Muenster, Germany. Institute of Neuropathology, University Hospital Muenster, Muenster, Germany. ${ }^{4}$ Division of Pediatric Neurooncology, German Cancer Research Center (DKFZ), Heidelberg, Germany. ${ }^{5}$ Institute of Biostatistics and Clinical Research, WestfalianWilhelms University, Muenster, Germany. ${ }^{6}$ Institute of Pharmaceutical Sciences, Freiburg, Germany. ${ }^{7}$ Childrens' Hospital Augsburg, Swabian Childrens' Cancer Center, Klinikum Augsburg Stenglinstr 2, Augsburg 86156, Germany.

Received: 20 May 2013 Accepted: 4 June 2013

Published: 13 June 2013

\section{References}

1. Sakuma T, Uzawa K, Onda T, Shiiba M, Yokoe H, Shibahara T, Tanzawa H: Aberrant expression of histone deacetylase 6 in oral squamous cell carcinoma. Int J Oncol 2006, 29(1):117-124.

2. Wilson AJ, Byun DS, Popova N, Murray LB, L'Italien K, Sowa Y, Arango D, Velcich A, Augenlicht LH, Mariadason JM: Histone deacetylase 3 (HDAC3) and other class I HDACs regulate colon cell maturation and p21 expression and are deregulated in human colon cancer. J Biol Chem 2006, 281(19):13548-13558.

3. Minucci S, Pelicci PG: Histone deacetylase inhibitors and the promise of epigenetic (and more) treatments for cancer. Nat Rev Cancer 2006, 6(1):38-51.

4. Camphausen K, Cerna D, Scott T, Sproull M, Burgan WE, Cerra MA, Fine $\mathrm{H}$, Tofilon PJ: Enhancement of in vitro and in vivo tumor cell radiosensitivity by valproic acid. Int J Cancer 2005, 114(3):380-386.

5. Dowdy SC, Jiang S, Zhou XC, Hou X, Jin F, Podratz KC, Jiang SW: Histone deacetylase inhibitors and paclitaxel cause synergistic effects on apoptosis and microtubule stabilization in papillary serous endometrial cancer cells. Mol Cancer Ther 2006, 5(11):2767-2776.

6. Kim IA, Shin JH, Kim IH, Kim JH, Kim JS, Wu HG, Chie EK, Ha SW, Park Cl, Kao GD: Histone deacetylase inhibitor-mediated radiosensitization of human cancer cells: class differences and the potential influence of p53. Clin Cancer Res 2006, 12 (3 Pt 1):940-949.

7. Dokmanovic M, Marks PA: Prospects: histone deacetylase inhibitors. J Cell Biochem 2005, 96(2):293-304.

8. Rasheed WK, Johnstone RW, Prince HM: Histone deacetylase inhibitors in cancer therapy. Expert Opin/nvestig Drugs 2007, 16(5):659-678.

9. Furchert SE, Lanvers-Kaminsky C, Juurgens $H$, Jung M, Loidl A, Fruhwald MC: Inhibitors of histone deacetylases as potential therapeutic tools for high-risk embryonal tumors of the nervous system of childhood. Int $J$ Cancer 2007, 120(8):1787-1794.

10. Muhlisch J, Schwering A, Grotzer M, Vince GH, Roggendorf W, Hagemann C, Sorensen N, Rickert CH, Osada N, Jurgens $\mathrm{H}$, et al: Epigenetic repression of RASSF1A but not CASP8 in supratentorial PNET (sPNET) and atypical teratoid/ rhabdoid tumors (AT/RT) of childhood. Oncogene 2006, 25(7):1111-1117.

11. Thiemann M, Oertel S, Ehemann V, Weichert W, Stenzinger A, Bischof M, Weber K, Perez RL, Haberkorn U, Kulozik AE, et al: In vivo efficacy of the histone deacetylase inhibitor suberoylanilidehydroxamic acid in combination with radiotherapy in a malignant rhabdoid tumor mouse model. RadiatOncol 2012, 7:52. 
12. Biegel JA: Molecular genetics of atypical teratoid/rhabdoid tumor. Neurosurg Focus 2006, 20(1):E11

13. Versteege I, Sevenet $N$, Lange J, Rousseau-Merck MF, Ambros P, Handgretinger $\mathrm{R}$, Aurias A, Delattre O: Truncating mutations of hSNF5/INI1 in aggressive paediatric cancer. Nature 1998, 394(6689):203-206.

14. Sultan I, Qaddoumi I, Rodriguez-Galindo C, Nassan AA, Ghandour K, Al-Hussaini M: Age, stage, and radiotherapy, but not primary tumor site, affects the outcome of patients with malignant rhabdoid tumors. Pediatr Blood Cancer 2010, 54(1):35-40.

15. Kieran MW, Roberts CW, Chi SN, Ligon KL, Rich BE, Macconaill LE, Garraway LA, Biegel JA: Absence of oncogenic canonical pathway mutations in aggressive pediatric rhabdoid tumors. Pediatr Blood Cancer 2012, 59(7):1155-1157.

16. Hasselblatt M, Isken S, Linge A, Eikmeier K, Jeibmann A, Oyen F, Nagel I, Richter J, Bartelheim K, Kordes U, et al: High-resolution genomic analysis suggests the absence of recurrent genomic alterations other than SMARCB1 aberrations in atypical teratoid/rhabdoid tumors. Genes Chromosomes Cancer 2013, 52(2):185-190.

17. Versteege I, Medjkane S, Rouillard D, Delattre O: A key role of the hSNF5/ INI1 tumour suppressor in the control of the G1-S transition of the cell cycle. Oncogene 2002, 21(42):6403-6412.

18. Tsikitis M, Zhang Z, Edelman W, Zagzag D, Kalpana GV: Genetic ablation of Cyclin D1 abrogates genesis of rhabdoid tumors resulting from Ini1 loss. ProcNat/AcadSci U S A 2005, 102(34):12129-12134.

19. Jagani Z, Mora-Blanco EL, Sansam CG, McKenna ES, Wilson B, Chen D, Klekota J, Tamayo P, Nguyen PT, Tolstorukov M, et al: Loss of the tumor suppressor Snf5 leads to aberrant activation of the Hedgehog-Gli pathway. Nat Med 2010, 16(12):1429-1433.

20. Zhang ZK, Davies KP, Allen J, Zhu L, Pestell RG, Zagzag D, Kalpana GV: Cell cycle arrest and repression of cyclin D1 transcription by INI1/hSNF5. Mol Cell Biol 2002, 22(16):5975-5988.

21. Wilson BG, Wang X, Shen X, McKenna ES, Lemieux ME, Cho YJ, Koellhoffer EC, Pomeroy SL, Orkin SH, Roberts CW: Epigenetic antagonism between polycomb and SWI/SNF complexes during oncogenic transformation. Cancer Cell 2010, 18(4):316-328.

22. Chou TC, Talalay P: Quantitative analysis of dose-effect relationships: the combined effects of multiple drugs or enzyme inhibitors. Adv Enzyme Regul 1984, 22:27-55.

23. Ben-Porath I, Thomson MW, Carey VJ, Ge R, Bell GW, Regev A, Weinberg RA: An embryonic stem cell-like gene expression signature in poorly differentiated aggressive human tumors. Nat Genet 2008, 40(5):499-507.

24. Vernell $\mathrm{R}$, Helin $\mathrm{K}$, Muller $\mathrm{H}$ : Identification of target genes of the p16INK4A-pRB-E2F pathway. J Biol Chem 2003, 278(46):46124-46137.

25. Birks DK, Donson AM, Patel PR, Dunham C, Muscat A, Algar EM, Ashley DM, Kleinschmidt-Demasters BK, Vibhakar R, Handler MH, et al: High expression of BMP pathway genes distinguishes a subset of atypical teratoid/rhabdoid tumors associated with shorter survival. Neuro Oncol 2012, 13(12):1296-1307.

26. Roth RB, Hevezi P, Lee J, Willhite D, Lechner SM, Foster AC, Zlotnik A: Gene expression analyses reveal molecular relationships among 20 regions of the human CNS. Neurogenetics 2006, 7(2):67-80.

27. Takami $\mathrm{Y}$, Nishi $\mathrm{R}$, Nakayama $\mathrm{T}$ : Histone $\mathrm{H} 1$ variants play individual roles in transcription regulation in the DT40 chicken B cell line. BiochemBiophys Res Commun 2000, 268(2):501-508.

28. Hezroni H, Sailaja BS, Meshorer E: Pluripotency-related, valproic acid (VPA)-induced genome-wide histone H3 lysine 9 (H3K9) acetylation patterns in embryonic stem cells. J Biol Chem 2011, 286(41):35977-35988.

29. Knipstein JA, Birks DK, Donson AM, Alimova I, Foreman NK, Vibhakar R: Histone deacetylase inhibition decreases proliferation and potentiates the effect of ionizing radiation in atypical teratoid/rhabdoid tumor cells. Neuro Oncol 2012, 14(2):175-183.

30. Qiu L, Burgess A, Fairlie DP, Leonard H, Parsons PG, Gabrielli BG: Histone deacetylase inhibitors trigger a G2 checkpoint in normal cells that is defective in tumor cells. MolBiol Cell 2000, 11(6):2069-2083.

31. Zain J, O'Connor OA: Targeting histone deacetyalses in the treatment of B- and T-cell malignancies. Invest New Drugs 2010, 28(Suppl 1):S58-S78.

32. Betz BL, Strobeck MW, Reisman DN, Knudsen ES, Weissman BE: Re-expression of hSNF5/INI1/BAF47 in pediatric tumor cells leads to G1 arrest associated with induction of p16ink4a and activation of RB. Oncogene 2002, 21(34):5193-5203.

33. Alarcon-Vargas D, Zhang Z, Agarwal B, Challagulla K, Mani S, Kalpana GV: Targeting cyclin D1, a downstream effector of INI1/hSNF5, in rhabdoid tumors. Oncogene 2006, 25(5):722-734.
34. Dragnev KH, Pitha-Rowe I, Ma Y, Petty WJ, Sekula D, Murphy B, Rendi M, Suh N, Desai NB, Sporn MB, et al: Specific chemopreventive agents trigger proteasomal degradation of $\mathrm{G} 1$ cyclins: implications for combination therapy. Clin Cancer Res 2004, 10(7):2570-2577.

35. Fleming AJ, Hukin J, Rassekh R, Fryer C, Kim J, Stemmer-Rachamimov A, Birks DK, Huang A, Yip S, Dunham C: Atypical TeratoidRhabdoid Tumors (ATRTs): The British Columbia's Children's Hospital's Experience, 1986-2006. Brain Pathol 2012, 22(5):625-635.

36. Lee RS, Stewart C, Carter SL, Ambrogio L, Cibulskis K, Sougnez C, Lawrence MS, Auclair D, Mora J, Golub TR, et al: A remarkably simple genome underlies highly malignant pediatric rhabdoid cancers. J Clin Invest 2012, 122(8):2983-2988.

37. McKenna ES, Tamayo P, Cho YJ, Tillman EJ, Mora-Blanco EL, Sansam CG, Koellhoffer EC, Pomeroy SL, Roberts CW: Epigenetic inactivation of the tumor suppressor BIN1 drives proliferation of SNF5-deficient tumors. Cell Cycle 2012, 11(10):1956-1965.

38. Watanabe M, Adachi S, Matsubara H, Imai T, Yui Y, Mizushima Y, Hiraumi Y, Watanabe K, Kamitsuji Y, Toyokuni SY, et al: Induction of autophagy in malignant rhabdoid tumor cells by the histone deacetylase inhibitor FK228 through AIF translocation. Int J Cancer 2009, 124(1):55-67.

39. Algar EM, Muscat A, Dagar V, Rickert C, Chow CW, Biegel JA, Ekert PG, Saffery R, Craig J, Johnstone RW, et al: Imprinted CDKN1C is a tumor suppressor in rhabdoid tumor and activated by restoration of SMARCB1 and histone deacetylase inhibitors. PLoS One 2009, 4(2):e4482.

40. Paternot S, Bockstaele L, Bisteau X, Kooken H, Coulonval K, Roger PP: $\mathrm{Rb}$ inactivation in cell cycle and cancer: the puzzle of highly regulated activating phosphorylation of CDK4 versus constitutively active CDK-activating kinase. Cell Cycle 2010, 9(4):689-699.

41. Northcott PA, Korshunov A, Witt H, Hielscher T, Eberhart CG, Mack S, Bouffet E, Clifford SC, Hawkins CE, French P, et al: Medulloblastoma comprises four distinct molecular variants. J ClinOncol 2011, 29(11):1408-1414.

42. Rudin CM, Hann CL, Laterra J, Yauch RL, Callahan CA, Fu L, Holcomb T, Stinson J, Gould SE, Coleman B, et al: Treatment of medulloblastoma with hedgehog pathway inhibitor GDC-0449. N Engl J Med 2009, 361(12):1173-1178.

43. Villablanca JG, London WB, Naranjo A, McGrady P, Ames MM, Reid JM, McGovern RM, Buhrow SA, Jackson H, Stranzinger E, et al: Phase II study of oral capsular 4-hydroxyphenylretinamide (4-HPR/fenretinide) in pediatric patients with refractory or recurrent neuroblastoma: a report from the Children's Oncology Group. Clin Cancer Res 2011, 17(21):6858-6866.

44. Dokmanovic M, Clarke C, Marks PA: Histone deacetylase inhibitors: overview and perspectives. Mol Cancer Res 2007, 5(10):981-989.

45. Marks PA, Richon VM, Breslow R, Rifkind RA: Histone deacetylase inhibitors as new cancer drugs. CurrOpinOncol 2001, 13(6):477-483.

46. Garcia-Manero G, Tambaro FP, Bekele NB, Yang H, Ravandi F, Jabbour E, Borthakur G, Kadia TM, Konopleva MY, Faderl S, et al: Phase II trial of vorinostat with idarubicin and cytarabine for patients with newly diagnosed acute myelogenous leukemia or myelodysplastic syndrome. J ClinOncol 2012, 30(18):2204-2210.

47. Ramaswamy B, Fiskus W, Cohen B, Pellegrino C, Hershman DL, Chuang E, Luu T, Somlo G, Goetz M, Swaby R, et al: Phase I-Il study of vorinostat plus paclitaxel and bevacizumab in metastatic breast cancer: evidence for vorinostat-induced tubulin acetylation and $\mathrm{Hsp} 90$ inhibition in vivo. Breast Cancer Res Treat 2012, 132(3):1063-1072.

48. Walter RB, Medeiros BC, Powell BL, Schiffer CA, Appelbaum FR, Estey EH: Phase II trial of vorinostat and gemtuzumabozogamicin as induction and post-remission therapy in older adults with previously untreated acute myeloid leukemia. Haematologica 2012, 97(5):739-742.

49. Friday BB, Anderson SK, Buckner J, Yu C, Giannini C, Geoffroy F, Schwerkoske J, Mazurczak M, Gross H, Pajon E, et al: Phase II trial of vorinostat in combination with bortezomib in recurrent glioblastoma: a north central cancer treatment group study. Neuro Oncol 2012, 14(2):215-221.

50. Fouladi M, Park JR, Stewart CF, Gilbertson RJ, Schaiquevich P, Sun J, Reid JM, Ames MM, Speights R, Ingle AM, et al: Pediatric phase I trial and pharmacokinetic study of vorinostat: a Children's Oncology Group phase I consortium report. J ClinOncol 2010, 28(22):3623-3629.

doi:10.1186/1471-2407-13-286

Cite this article as: Kerl et al: The histone deacetylase inhibitor SAHA acts in synergism with fenretinide and doxorubicin to control growth of rhabdoid tumor cells. BMC Cancer 2013 13:286. 